\title{
Efficacy and Safety of Autologous Platelet Concentrate in the Treatment of Photoaging on the Back of the Hands
}

\author{
Israel Alfonso Trujillo*, Yetter Cruz Leon, Charllonne Angelica Marte Arias, Yaquelin Luciana Morales Novo, \\ Jesus Lazaro Diego De la Campa, Angela Rosa Gutierrez Rojas, Julio Antonio López Silva and Daymi Serpa \\ Almaguer \\ Clinical Surgical Hospital Hermanos Ameijeiras, Cuba
}

Submission: April 08, 2021; Published: April 26, 2020

*Corresponding author: Israel Alfonso Trujillo, Clinical Surgical Hospital Hermanos Ameijeiras. Havana, Cuba

\begin{abstract}
Introduction: From the fourth decade of life (especially on the back of the hands) the skin becomes dry and brittle, spots appear, the venous network increases and soft tissues decrease.
\end{abstract}

Objective: To evaluate the efficacy and safety of intradermal microinjection of autologous platelet concentrate (APC) in the treatment of rejuvenation of the back of the hands.

Method: An observational, analytical and longitudinal study was carried out in 60 patients from the Hospital Clínico Quirúrgico: "Hermanos Ameijeiras", in the period between March 1, 2017 and March 31, 2020. The treatment was applied monthly for 1 year. The final evaluation was carried out 3 months after the end of the treatment.

Results: 51 women with an average age of $45 \pm 4.3$ years were treated. After treatment, there were significant changes in the Glogau photodamage scale $(p=0.012)$, in the global scale of aesthetic improvement $(p<0.001)$ and in the scale of the degree of involvement of the volume of the hand $(\mathrm{p}=0.018)$. The adverse events found were pain, inflammation and ecchymosis. The degree of satisfaction reported by the patients was good $(26.6 \%)$ and very good $(73.4 \%)(p<0.001)$.

Conclusion: The autologous platelet concentrate proved to be effective and safe in reducing the signs of cutaneous aging on the back of the hands, associated with a high degree of patient satisfaction.

Keywords: Platelet-rich plasma; Rejuvenation; Photoaging; Autologous platelet concentrate

\section{Introduction}

From the fourth decade of life, the skin becomes dry and brittle, spots appear, red vein increases and soft tissues decrease, especially on the back of the hands. To achieve rejuvenation of the hands, the aesthetic doctor must combine and adapt various treatments. Platelet-rich plasma (PRP) and its growth factors (GF) have a recognized revitalizing, regenerative and biorepairing effect, $[1,2]$ however few studies objectively evaluate their efficacy, which led to the realization of the present investigation.

\section{Goals}

The primary objective was: to determine the effectiveness and safety of the microinjection of autologous platelet concentrate
(APC) in the treatment of photoaging of the back of the hands and the secondary objectives were: 1) to evaluate the clinical response to treatment, 2) to evaluate type and intensity of adverse events that occur and 3) describe the degree of patient satisfaction.

\section{Method}

An observational, analytical, longitudinal study was carried out in 60 patients at the Hospital Clínico Quirúrgico: "Hermanos Ameijeiras", in the period between March 1, 2017 and March 31, 2020. Treatment with APC was applied monthly for 12 months. Three months after the end of the treatment, the response to it was sent (final evaluation), comparing the current state (soft tissues, veins, tendons and skin) with the initial state; for this, the 
patient had to attend the scheduled consultation. Throughout the study there was a rigorous control of adverse reactions. Before and after proceeding, the platelets were quantified to know the quality of the applied product (the average concentration of the platelets after advancing 10.8 times its initial value). Microbiological culture of the extracted plasma was performed to guarantee that a sterile germ product was administered.

Table 1: Classification of photoaging according to Glogau [3].

\section{Inclusion criteria}

Patients between 20 and 60 years old, of any sex and skin phototype, skin photoaging grade II, III and IV (Glogau classification) (Table 1), [3] grade 1 to 3 according to scale of the degree of affectation of the volume of the (HVRS) (Table 2), [4] normal complementary tests (hemogram with differential, coagulogram, blood chemistry and serology for HIV, hepatitis B and C), with signed informed consent.

\begin{tabular}{|c|c|}
\hline Type & Characterization \\
\hline $\begin{array}{l}\text { Type I } \\
\text { "No wrinkles" }\end{array}$ & $\begin{array}{c}\text { Early photoaging: slight pigmentary changes, no keratosis, minimal wrinkles, no scars, young patient, generally } 28-35 \\
\text { years of age, no or minimal makeup. }\end{array}$ \\
\hline $\begin{array}{l}\text { Type II } \\
\text { "Movement wrinkles" }\end{array}$ & $\begin{array}{l}\text { Early to moderate photoaging: visible early senile lentigo, early actinic keratosis, slight signs of scars, wrinkles and } \\
\text { parallel smile lines begin to appear, patient age: late 30s or 40s, usually she wears some makeup. }\end{array}$ \\
\hline $\begin{array}{l}\text { Type III } \\
\text { "Wrinkles at rest" }\end{array}$ & $\begin{array}{l}\text { Advanced photoaging: obvious dyschromia and telangiectasias, visible keratoses, neoplasms (+), wrinkles even when } \\
\text { not moving, patient age: fifty years or older, always wears a lot of makeup. }\end{array}$ \\
\hline $\begin{array}{l}\text { Type IV } \\
\text { "Wrinkles only" }\end{array}$ & $\begin{array}{l}\text { Intense photoaging: grayish-yellow skin, cutaneous neoplasms (+++), all wrinkled skin, no normal skin, age of patient: } \\
\text { sixties or seventies, cannot wear makeup, "hard and cracked". }\end{array}$ \\
\hline
\end{tabular}

Table 2: Hand volume involvement scale (HVRS) [4].

\begin{tabular}{|c|c|c|}
\hline Grade & & Characteristics \\
\hline 0 & Absent & No loss of soft tissue, veins not visible or only superficially visible and no visible tendons. \\
\hline 1 & Minimal & Minimal soft tissue loss, only slightly prominent and visible or no tendons. \\
\hline 2 & Moderate & Moderate loss of soft tissue, prominent veins, and markedly visible tendons. \\
\hline 3 & Moderately severe & $\begin{array}{l}\text { Moderately severe soft tissue loss, very prominent veins, substantially protruding tendons (most tendons } \\
\text { visible), rough skin, and presence of fine wrinkles. All the aforementioned conditions are mandatory. }\end{array}$ \\
\hline 4 & Severe & $\begin{array}{c}\text { Severe soft tissue loss, markedly prominent veins, extremely protruding tendons (all tendons visible), very } \\
\text { rough skin with dermal atrophy, and severe presence of fine wrinkles. All the aforementioned conditions are } \\
\text { required. }\end{array}$ \\
\hline
\end{tabular}

\section{Exclusion criteria (Table 3)}

\section{Elimination criteria}

Patients who wish to abandon the study, presence of an adverse event and / or complication that prevents continuing with the treatment or patients who have missed a treatment session.

\section{Procedures}

Once the patients gave informed consent, the included subjects registry template and the investigator's internal registry were filled out. All information on the included patients was compiled in the data collection notebook. The blood was extracted (500 milliliters), then the APC was obtained with the Rotixa centrifuge (221 mm radius) according to international standards [5]. To obtain the APC, a first light centrifugation of the whole blood was carried out in the plastic bag for 3 minutes at $2800 \mathrm{rpm}$ at $22{ }^{\circ} \mathrm{C}$, with a centrifugation force of $2000 \mathrm{~g}$, in this way $250 \mathrm{ml}$ of red blood cells and $250 \mathrm{ml}$ were obtained of PRP; then a second weighted centrifugation was performed on the PRP in the plastic bag for 5 minutes at $4500 \mathrm{rpm}$ at $22^{\circ} \mathrm{C}$, with a centrifugation force of $5000 \mathrm{~g}$. Once the heavy centrifugation had been carried out, the supernatant plasma was transferred through the tubes that have the plastic bags for blood collection and only $10 \mathrm{ml}$ were left and it is in said volume that by shaking the platelets that were deposited in the cell were resuspended. bottom of the bag as results of the centrifugation procedure. Subsequently, the red blood cells were returned to the patients and finally a microinjection of 10 milliliters of the APC was performed, distributed between the back of the hands, the entire facial area, $\mathrm{V}$ of the décolleté and neck. 
Table 3: Exclusion criteria and their relationship with the time limits to perform the procedure.

\begin{tabular}{|c|c|}
\hline Criteria & Time limits \\
\hline Congenital or acquired coagulation disorders. & Prior and simultaneous to the procedure \\
\hline Bone marrow aplasia. & Prior and simultaneous to the procedure \\
\hline Prone to forming keloids. & Before the procedure \\
\hline $\begin{array}{c}\text { Cardiovascular or pacemaker, neurological, liver, kidney, endocrine or immunological } \\
\text { diseases, decompensated. }\end{array}$ & Simultaneous to the procedure \\
\hline $\begin{array}{l}\text { Severe psychiatric disorder or other limitation that prevents the patient from giving his } \\
\text { informed consent or makes his evaluation difficult. }\end{array}$ & Simultaneous to the procedure \\
\hline Pregnancy or breastfeeding & Simultaneous to the procedure \\
\hline $\begin{array}{l}\text { Treatment with anticoagulants, antifibrinolytics, macrolides, terfenadine, cimetidine, } \\
\text { amiodarone, fluoxetine, NSAIDs, or corticosteroids. }\end{array}$ & One month prior to the procedure \\
\hline $\begin{array}{l}\text { Application of topical retinoids, aesthetic treatments in the region to be treated, includ- } \\
\text { ing lasers, intense pulsed light, chemical peels, mesotherapy, carboxytherapy or others. }\end{array}$ & Three months prior to the procedure \\
\hline Fillers in the region to be treated. & One year prior to the procedure \\
\hline Active neoplastic diseases or during the follow-up period & Five years post-healing prior to the procedure \\
\hline
\end{tabular}

Asepsis and antisepsis of the back of the hands were performed. Radial and ulnar nerve block was performed by subcutaneous infiltration of $3 \mathrm{ml}$ of $2 \%$ lidocaine close to the styloid process of the radius (anatomical tobacco box) and another $3 \mathrm{ml}$ of $2 \%$ lidocaine at the level of the styloid process of the ulna (between the flexor carpi ulnaris tendon and the ulnar artery). Once the APC was activated with $10 \%$ calcium gluconate (concentration 10:1), it was administered by combining cannulas and needles. Punctures were made with a 20G needle at the level of the dorsal surface of the second, third and fourth interdigital spaces and through these punctures a $1 \mathrm{~mm} \times 10 \mathrm{~cm}$ long cannula with a blunt tip was introduced, with which the APC was administered by Table 4: Global aesthetic improvement scale (GAIS) [6]. subcutaneously (fan and backtracking techniques). Subsequently, with a $25 \mathrm{G} \times 16 \mathrm{~mm}$ hypodermic needle and $1 \mathrm{ml}$ syringes, intradermal injections of approximately $1.5 \mathrm{ml}$ were administered at a distance of 1.5 to $2 \mathrm{~mm}$ between each application area (point-topoint, fan, backtrace and nappage).

\section{Variables related to the response to treatment}

The response to treatment was evaluated taking into account the clinical examination of the patient, using the Glogau photodamage scale (Table 1),[3] the global aesthetic improvement scale (GAIS) (Table 4)[6] and the scale of the degree of involvement of the volume of the hand (Table 2)[4].

\begin{tabular}{|c|c|c|}
\hline Evaluation & & Degree of improvement \\
\hline 1 & Total answer & $\begin{array}{l}\text { Patient with exceptional or much better improvement (excellent corrective result, total } \\
\text { disappearance of the lesions). }\end{array}$ \\
\hline 2 & Marked partial response & $\begin{array}{l}\text { Patient greatly improved or considerably better (marked improvement in appearance, } \\
\text { but not completely optimal, reduction of lesions by } \geq 50 \% \text { and }<100 \% \text { ). }\end{array}$ \\
\hline 3 & Slight partial response & $\begin{array}{l}\text { Improved or somewhat better patient (appearance slightly better than initial condition, } \\
\text { but needs more treatments, }<50 \% \text { lesions decrease). }\end{array}$ \\
\hline 4 & Non-response & No change (the same number and size of lesions as at the start of treatment). \\
\hline 5 & Progression & Worse (increased number or size of lesions). \\
\hline
\end{tabular}




\section{Adverse events}

Adverse events reported in the reviewed literature are pain, edema, and ecchymosis at the microinjection site [1,2].

\section{Classification of adverse events (Table 5)[7] \\ Degree of satisfaction of patients to treatment}

The degree of satisfaction (PSSS) of the patients with the treatment was evaluated taking into account what was reported by the patient according to the scale (Table 6) [8].

\section{Bioethical considerations}

The protocol was submitted to the consideration and approval of a Review and Ethics Committee for Clinical Research created for this purpose, which evaluated it from an ethical point of view. Additionally, this protocol was submitted to scientific and methodological review and approval by the Institutional Scientific Council of the Hospital Clínico Quirúrgico "Hermanos Ameijeiras".

Table 5: Intensity scale of adverse events [7].

\begin{tabular}{|c|r|}
\hline Intensity & Characteristics \\
\hline Mild & if the adverse event subsided without treatment. \\
\hline Moderate & if treatment was required, but the adverse event subsided with it. \\
\hline Serious & if hequired hospitalization or did not yield to treatment. \\
\hline Very serious & if it endangered the life of the patient, if it caused sequelae or disability. \\
\hline
\end{tabular}

Table 6: Scale of the degree of patient satisfaction [8].

\begin{tabular}{|c|c|c|}
\hline Evaluation & & Degree of satisfaction \\
\hline 1 & Very bad & I did not get any improvement and the treatment caused me multiple discomforts (inflammation, bruising and \\
pain).
\end{tabular}

\section{Statistical methods used}

The medical records of the patients included in the study were stored in the Department's file. With the information gathered, a Microsoft Office version XP database in Excel format was created, which was exported to the SPSS version 21.0 system for analysis. To summarize the information of the study sample, the arithmetic mean, standard deviation and minimum and maximum values will be used. The Student's t test was used for all quantitative variables. For all qualitative variables (degree of aesthetic improvement, degree of affectation of the volume of the hand and degree of satisfaction), the absolute numbers and percentages were calculated before and after the treatment, which were compared using Pearson's Chi-square test. In all the hypothesis tests carried out, a significance level $\alpha=0.05$ was performed.

\section{Sample's size calculation}

The sample size was calculated using the C4-Study Design Pack computerized program. (C4- SDP) for sample size calcula- tion (CTM). Version 1.1 ® Glaxo Wellcome. SA; [9] considering the following values: percentage of success reported in the literature $70 \%$, percentage of success in the current study of $80 \%$. With an alpha error of 0.05 , a power of $80 \%$ and covering a loss of $5 \%$ of the patients, it was necessary to have 60 subjects in total.

\section{Results}

The study sample consisted of 60 women with skin phototypes between II and IV. The average age ranged around $45 \pm 4.3$ years (Table 7). Regarding the Glogau Photodamage Scale, 51 patients were classified as grade III, and 9 as grade II before the start of the study. After treatment, 33/51 (64.7\%) patients who were classified as grade III were reclassified as grade II and 6/9 (66.6\%) patients who were classified as grade II were reclassified as grade I ( $p=0.012)$; the rest of the patients remained in the same grade assigned before treatment. According to the Global Esthetic Improvement Scale, there were significant changes after treatment ( $\mathrm{p}<0.001) ; 3 / 60(5 \%)$ patients achieved a total response, 37/60 $(61.6 \%)$ patients achieved a marked partial response, and 20/60 


\section{Juniper Online Journal of Dermatology \& Cosmetics}

(33.3\%) patients achieved a slight partial response (Figure 1\& 2). the hand, 51 patients were classified as grade III, 6 as grade II and Regarding the Scale of the degree of involvement of the volume of 3 as grade I before the start of the study.
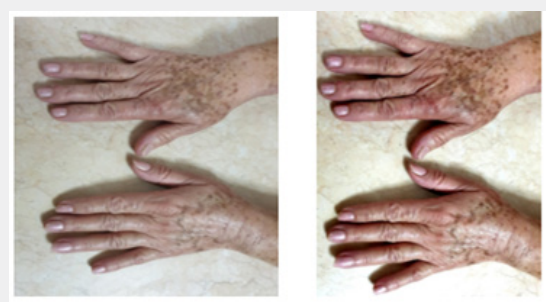

(A)
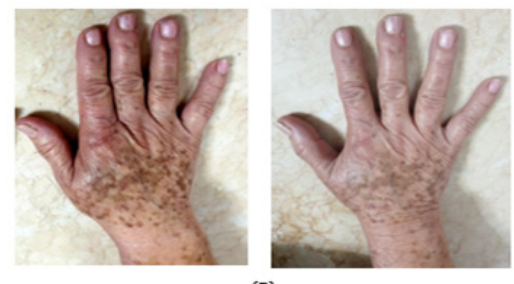

(B)

Figure 1: Images showing the improvement of the skin on the back of the hands of a patient (A) before and (B) three months after treatment with APC.

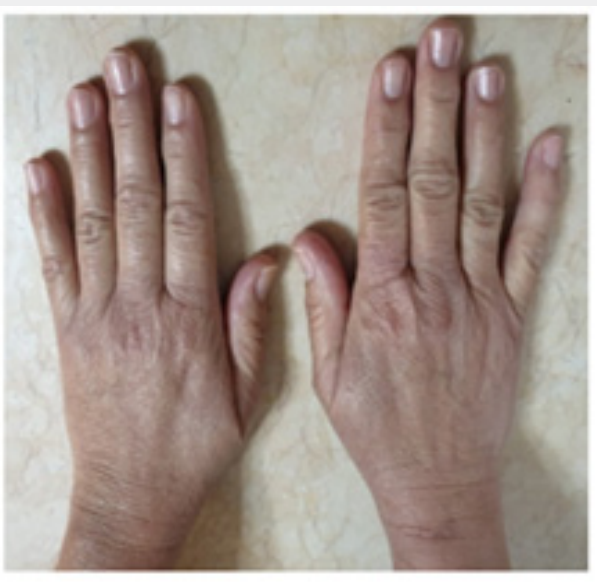

(A)

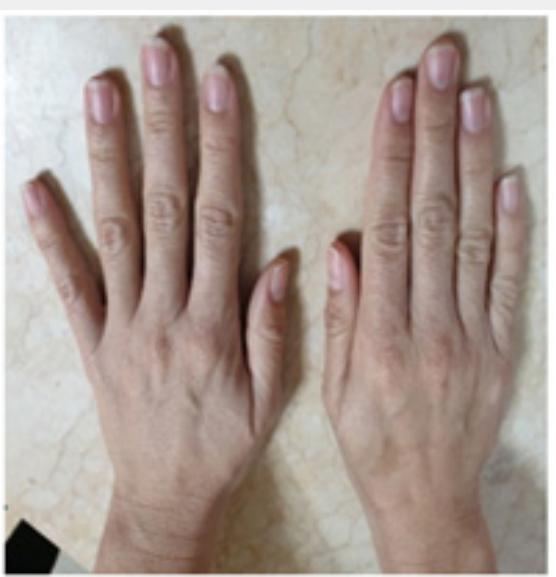

(B)

Figure 2: Images showing the improvement of the skin on the back of the hands of another patient $(A)$ before and $(B)$ three months after treatment with APC.

Table 7: Epidemiological and clinical characteristics of the subjects.

\begin{tabular}{|c|c|c|c|}
\hline \multirow{4}{*}{ Age } & Mean (SD) & \multicolumn{2}{|c|}{$\mathbf{4 5 . 6}(\mathbf{\pm 4 . 3 )}$} \\
\cline { 2 - 4 } & (Minimum; Maximum) & $\mathbf{2 7}$. 58) \\
\cline { 2 - 4 } & & 15 & 25 \\
\cline { 2 - 4 } & $20-29$ & 12 & 20 \\
\cline { 2 - 4 } & $30-39$ & 27 & 45 \\
\cline { 2 - 4 } & $40-49$ & 6 & 10 \\
\hline \multirow{2}{*}{ Sex } & $50-60$ & 60 & 100 \\
\hline
\end{tabular}


Juniper Online Journal of Dermatology \& Cosmetics

\begin{tabular}{|c|c|c|c|}
\hline \multirow{3}{*}{ Skin phototype } & II & 24 & 40,0 \\
\cline { 2 - 4 } & III & 33 & 55 \\
\cline { 2 - 4 } & IV & 3 & 5 \\
\hline \multirow{3}{*}{ Glogau } & II & 51 & 85 \\
\cline { 2 - 4 } & III & 3 & 5 \\
\hline \multirow{3}{*}{ HVRS } & Si1 & 6 & 10 \\
\cline { 2 - 4 } & 2 & 51 & 85 \\
\hline
\end{tabular}

Table 8: Adverse events.

\begin{tabular}{|c|c|c|c|}
\hline \multicolumn{2}{|c}{} & \multicolumn{2}{c|}{ APC } \\
\multicolumn{2}{|c|}{} & \multicolumn{2}{c|}{ N=60 } \\
\cline { 3 - 4 } \multicolumn{2}{|c|}{} & N & \% \\
\hline \multirow{2}{*}{ Adverse events } & Pain & 60 & 100 \\
\cline { 2 - 4 } & Inflammation & 50 & 83.3 \\
\cline { 2 - 4 } & Equimosis & 10 & 16.7 \\
\hline Duration & Less than 7 Days & 60 & 100 \\
\hline intensity & Light & 60 & 100 \\
\hline Attitude & No Changes & 60 & 100 \\
\hline Result & Resolved & 60 & 100 \\
\hline
\end{tabular}

Table 9: Degree of satisfaction, according to the patients' own satisfaction scale (PSSS).

\begin{tabular}{|c|c|c|c|}
\hline \multirow{2}{*}{ Satisfaction } & \multicolumn{2}{|c|}{$\begin{array}{c}\text { APC } \\
N=60\end{array}$} & \multirow[t]{2}{*}{$\mathbf{p}$} \\
\hline & $\mathbf{N}$ & $\%$ & \\
\hline Regular & 0 & 0 & \multirow{3}{*}{$<0.001\left(\mathrm{x}^{2}\right)$} \\
\hline Good & 16 & 26.6 & \\
\hline Very Good & 44 & 73.4 & \\
\hline
\end{tabular}

After treatment, 35/51 (68.6\%) patients who were classified as grade III were reclassified as grade II, $4 / 6(66.6 \%)$ patients who were classified as grade II were reclassified as grade I and 2 / 3 $(66.6 \%)$ patients who were classified as grade I were reclassified as grade $0(p=0.018)$; the rest of the patients remained in the same grade assigned before treatment. All the patients reported some adverse event (pain, inflammation and ecchymosis), which were of slight intensity, did not imply changes before the intervention and were completely resolved. The pain occurred during the procedure and disappeared immediately after the completion of the procedure (100\%), the inflammation $(83.3 \%)$ lasted 2 to 3 days and the ecchymosis at the puncture sites $(16.7 \%)$ were infrequent and of short duration (five to seven days in duration) (Table 8). Of the 60 patients treated with APC, $16 / 60$ patients (26.6\%) reported a good degree of satisfaction and a very good degree of satisfaction $44 / 60$ patients (73.4\%), because they achieved evident improvement with respect to their condition initial (Table 9).

\section{Discussion}

Platelets play a vital role in initiating hemostasis and wound healing. In response to tissue and vascular damage, a platelet plug is formed, with the subsequent release from its alpha granules of more than 30 biologically active proteins, including: transforming growth factor $\beta$, platelet-derived factor, growth factor, vascular endothelial growth factor, fibroblast growth factor, and epithelial cell growth factor. These factors not only aid in clotting but also drive angiogenesis and promote tissue repair and regeneration [10]. Multiple authors have shown that topical application or intradermal injection of PRP and its growth factors produce favorable cutaneous changes: clinical (restores its vitality, increases its thickness, recovers its elastic consistency, improves blood circulation, increases its smoothness, decreases its wrinkles and improves their appearance) $[2,10,11]$ histopathological (increases the number of fibroblasts, collagen fibers and blood vessel basement membranes) [2,10,12] immunohistochemical (improves collagen expression type I, III and IV) [13-15] and the genetic material (through the polymerase chain reaction expression of three target genes, such as: collagen IA, matrix metalloproteinase gene 1 and protein rich in proline of keratinocytes) $[13,14]$. PRP has been used as an adjunct to multiple skin rejuvenation treatments (lipotransference, laser, peeling, lifting).

In all the studies reviewed these treatments expected a higher response when combined than alone [12,16-18], PRP has also been used to reduce the intensity and duration of adverse events in these modalities. In a study by Kim H. and Gallo J, they were able to objectively reduce erythema and edema after treatment with fractional carbon dioxide laser by administering intradermal PRP $(P=0.02)$, associated with fewer subjective symptoms reported by patients (itching, burning and pain) [18]. There is only one previous report on the use of PRP as a rejuvenating monotherapy of the back of the hands, which was carried out by Cabrera-Ramírez JO and collaborators who applied 3 sessions of subcutaneous PRP with a cannula on the back of the hands. At the end of the treatment, the subjects had clinical improvement in the Fitzpatrick wrinkle and elastosis classification scale $(p<0.001)$ and in the Glogau photodamage scale $(p=0.01)$ and a histological increase in the number of fibroblasts $(\mathrm{p}=0.000)$, number of vessels $(\mathrm{p}=$ $0.000)$ and amount of collagen ( $p=0.27)$ [2]. In our study there was clinical improvement in the Glogau photodamage scale $(\mathrm{p}=$ 0.012), in the global scale of aesthetic improvement $(p=0.001)$ 
and in the scale of the degree of involvement of the volume of the hand $(\mathrm{p}=0.018)$.

\section{Conclusion}

The application of autologous platelet concentrate proved to be effective and safe in reducing the signs of skin aging on the back of the hands, associated with a high degree of patient satisfaction.

\section{References}

1. Fernández CA, Alfageme RF, Burón ÁI, Rodríguez SR, Villegas FC (2013) Bioestimulación cutánea con plasma rico en plaquetas autólogo. Estudio controlado con ecografía. Piel 28(2): 69-74.

2. Cabrera RJO, Puebla MAG, González OA, García MD, Cortés JA, et al. (2017) Plasma rico en plaquetas en el tratamiento del fotodaño cutáneo en las manos. Actas Dermosifiliogr 108(8): 746-751.

3. Glogau RG (1996) Aesthetic and anatomic analysis of the aging skin. Semin Cutan Med Surg 15(3): 134-138.

4. Hun LJ, Su CY, Soo PE, Seo KJ, Seok KM, et al. (2019) A novel photonumeric hand grading scale for hand rejuvenation. Arch Plast Surg 46(4): 359-364.

5. Nester T, AuBuchon JP (2013) Decisiones en hemoterpia y sus resultados. En: American Association of Banks Blood AABB. Manual Técnico de la AABB. 17a Ed. Buenos Aires: Asoc. Argentina Hemoterapia e Inmunohemat.

6. Savoia A, Accardo C, Vannini F, Pascale B, Baldi A (2014) Outcomes in thread lift for facial rejuvenation: a study performed with happy lift revitalizing. Dermatol Ther (Heidelb) 4(1): 103-114.

7. Moher D, Hopewell S, Schulz KF, Montori V, Gotzsche PC, et al. (2010) CONSORT 2010 Explanation and Elaboration: updated guidelines for reporting parallel group randomised trials. BMJ 340: c869.

8. Larson L, Rovers J, Mackeigan L (2002) Patient satisfaction with pharmaceutical care: update of a validated instrument. J Am Pharm Assoc 42(1): 44-50.

9. C4-Study Design Pack (C4- SDP) para el cálculo de tamaño de muestra (CTM). Versión 1.1®. Desarrollado por: Departamento de Biometría de Glaxo Wellcome.

10. Chamata ES, Bartlett EL, Weir D, Rohrich RJ (2021) Platelet-Rich Plasma: Evolving Role in Plastic Surgery. Plast Reconstr Surg 147(1): 219-30.

11. Devereaux J, Dargahi N, Fraser S, Nurgali K, Kiatos D (2020) LeucocyteRich Platelet-Rich Plasma Enhances Fibroblast and Extracellular Matrix Activity: Implications in Wound Healing. Int J Mol Sci 21(18): 6519.

12. El-Domyati M, Abdel-Wahab H. Hossam A (2018) Microneedling combined with platelet-rich plasma or trichloroacetic acid peeling for management of acne scarring: A split-face clinical and histologic comparison. J Cosmet Dermatol 17(1): 73-83.

13. Draelos ZD, Rheins LA, Wootten S, Kellar RS, Diller R (2019) Pilot study: Autologous platelet-rich plasma used in a topical cream for facial rejuvenation. J Cosmet Dermatol 18(5): 1348-1352.

14. Souza MV, Silva MB, Pinto O, Lima MB, Crepaldi J, et al. (2015) Immunohistochemical Expression of Collagens in the Skin of Horses Treated with Leukocyte-Poor Platelet-Rich Plasma. Biomed Res Int 2015: 893485.

15. Arora NS, Ramanayake T, Ren YF, Romanos GE (2009) Platelet-rich plasma: a literatura review. Implant Dent 18(4): 303-310.

16. Modarressi A (2013) Platlet Rich Plasma (PRP) Improves Fat Grafting Outcomes. World J Plast Surg 2(1): 6-13.

17. Puri N (2015) Platelet rich plasma in dermatology and aesthetic medicine. Our Dermatol Online 6(2): 207-211.

18. Kim H, Gallo J (2015) Evaluation of the Effect of Platelet-Rich Plasma on Recovery After Ablative Fractional Photothermolysis. JAMA Facial Plast Surg 17(2): 97-102.
This work is licensed under Creative

Commons Attribution 4.0 License

DOI: 10.19080/JOJDC.2021.04.555628 